\title{
Comparative Study Between Polydioxanone Unidirectional Barbed Suture and Absorbable Polyglactin Running Suture in Partial Nephrectomy
}

\author{
MIRCEA VALENTIN PIRVUT ${ }^{1}$, NICOLAE GRIGORE ${ }^{1,2 *}$, IONELA MIHAI ${ }^{1}$, ALEXANDRU TIBERIU PRIPOREANU ${ }^{3}$, \\ MIHAELA RACHERI $U^{1,2}$, DAN CRETU ${ }^{1,2}$, ADRIAN TEODORU ${ }^{1,2}$, DAN SABAU ${ }^{1,2}$, LOREDANA MITARIU ${ }^{1,2}$, REMUS RANGA ${ }^{1,2}$, \\ MARINELA MINODORA MANEA ${ }^{4,5}$, ADRIAN HASEGAN ${ }^{1,2}$ \\ ${ }^{1}$ Academic Emergency County Hospital, 2-4 Corneliu Coposu Str., 550245, Sibiu, Romania \\ ${ }^{2}$ Lucian Blaga University, Faculty of Medicine, 2A Lucian Blaga Str., 550169, Sibiu, Romania \\ ${ }^{3}$ Clinical Institute Fundeni, 258 Fundeni, 022328, Bucharest, Romania \\ ${ }^{4}$ UMF Iuliu Hatieganu, Department of Medical Psychology, 8 Victor Babes Str, 400012, Cluj Napoca, Romania \\ ${ }^{5}$ County Emergency Clinical Hospital Cluj Napoca, Psychiatric Clinic 3, 3-5 Clinicilor Str., 400000, Cluj-Napoca, Romania
}

Combining technological development in the laparoscopic field alongside the increase of surgeon's experience in partial nephrectomy, have extended the indications of laparoscopic nephron sparing surgery to more complicated cases, increasing the role of suture materials in obtaining a good collecting system closure and hemostasis, with short warm ischemia time and low postoperative complications rate. Suturing materials are continuously developed combining new and unique designs with novel synthetic materials in order to fulfill surgeon's exigence.

Keywords: polydioxanone, polyglactin, suture materials, partial nephrectomy

From the first surgeries performed, suture materials have represented an indispensable tool in surgeon's armamentarium, with a continuous evolution from vegetal and animal origin to synthetic composition.

Combining technological development in the laparoscopic field alongside the increase of surgeon's experience in partial nephrectomy, have extended the indications of laparoscopic nephron sparing surgery to more complicated cases such as pT2 tumours, multiple tumours, central and hilar masses, obese patient, concomitant in bloc adrenalectomy, tumor in horseshoe kidney, cystic tumours and tumours in a solitary functioning kidney [1], increasing the role of suture materials in obtaining a good collecting system closure and hemostasis, with short warm ischemia time and low postoperative complications rate.

Both barbed polydioxanone (V-Loc ${ }^{\mathrm{TM}}$ ) and polyglycolic acid (Bicril ${ }^{T M}$ ) are absorbable suture suitable for defect closure of renal parenchyma after nephron sparing surgery, with similar outcomes in term of intraoperative blood loss, complications rate and hospital stay [2].

\section{Experimental part}

In the present study we analized the intraoperative and postoperative outcomes of patients undergoing nephron sparing surgery and using V-Loc ${ }^{\mathrm{TM}}$ (Covidien) or Bicril ${ }^{\mathrm{TM}}$ (Biosintex) for closure of renal parenchyma defect.

We have analyzed 37 consecutive patients, between January 2014 and July 2017, who benefit from nephronsparing surgery for T1-T2 renal tumors. We have divided the patients in 2 group according to the suture materials used for renorrhaphy, Bicril 1 running suture for 21 patients witch was locked at both tail ends with Hem-0-lock clips, and for 16 patients we used V-loc ${ }^{\mathrm{TM}} 1$ running suture. For a more objective evaluation we organized the patients into 3 sub-groups according to risk group determined by preoperative zonal NePhRO scoring system.
A chart review was carried out, including age, sex, anatomic preoperative scoring system, operative time (skin opening to skin closing), estimated blood loss (EBL), warm inchemia time (WIT), hospital stay.

The perioperative complications w ere carefully graded using the Clavien-Dindo system.

The statistical analysis of this paper was done by using chi-square test, , the Fischer exact test. A p value $<0.05$ was considered statistically significant.

\section{Results and discussions}

The mean age of patients with partial nephrectomy was $54.3 \pm 9.1$ years. Mean preoperative serum creatinine level for the patient group was $0.97 \pm 0.14 \mathrm{mg} / \mathrm{dL}$. All patients had normal contralateral kidney. Average tumor diameter in this group was $3.6 \pm 0.86 \mathrm{~cm}$.

In patients with NePhRO score between 4-6, the type of suture utilized for renorrhaphy presented a strong statistically correlation with total operative time ( $p$ value of $<0.001$ ), estimated blood loss ( $p$ value 0.004 ) and warm time ischemia ( $p$ value 0.02 ). All features are presented in table 1.

In medium risk group the time of warm ischemia was significant shorter in V-loc ${ }^{\mathrm{TM}}$ suture than Bicril ${ }^{\mathrm{TM}}$ (17.7 min vs $20.8 \mathrm{~min}$ ) with a p value of 0.001 , but when we introduce in the equation the suture of collecting system that prolongues the ischemia time, the $p$ value increases to 0.05 , being at the limit of statistical significance. The rest of the outcomes are presented in table 2, and are comparable with the low risk group, except the hospital stay which becomes statistically relevant.

The high risk group is the most representative for this study because they do nothave major differences between patients that can influence the statistical analysis, all patients requiring collecting system suture.

Both operative time and estimated blood loss were higher in the Bicril ${ }^{T \mathrm{M}}$ group than V-loc ${ }^{\mathrm{TM}}$ group, $184.0 \mathrm{~min}$ 
vs. $158.0 \mathrm{~min}$ and $344.0 \mathrm{~mL}$ vs. $242.0 \mathrm{~mL}$, with a $p$ value of $<0.001$, respectively 0.01 (table 3 ).

Multiple authors reported significant reduce warm time ischemia for patients were unidirectional barbed suture was used for renorrhaphy [3-5], which correlates with our findings, $\mathrm{V}$-loc ${ }^{\mathrm{TM}}$ suture reducing the ischemia time by 27.9 $\%$ in comparison with Bicril suture.
Knowing that running suture reduce the warm ischemia time indifferent of tumor size and location [6], and laparoscopic knot tying is time consuming and often are weaker than those tied by hand in open surgery [7-9], we recommend for laparoscopic nephron sparing surgery by retroperitoneal approach (which provides little space for maneuver) a knotless running suture for rennorhaphy, with end-tails Hem-o-lock ${ }^{\mathrm{TM}}$ clips to secure the suture.

\begin{tabular}{|l|c|c|c|}
\hline & \multicolumn{2}{|c|}{ Low risk Zonal NePhRO score } & P value \\
& \multicolumn{2}{|c|}{ Bicril $^{\text {TM Group }}$} & \\
\hline Patients & 7 & 9 & n/a \\
\hline Operative time (min) \pm SD & $108.5 \pm 14.0(95-135)$ & $143.3 \pm 20.3(110-170)$ & $<0.001$ \\
(range) & & & \\
\hline Blood loss (m1) \pm SD (range) & $165.7 \pm 21.4(150-170)$ & $194.4 \pm 30.8(160-250)$ & 0.004 \\
\hline Warm ischemia time(min) & $16.0 \pm 3.0(14-18)$ & $18.2 \pm 2.03(17-25)$ & 0.02 \\
\pm SD (range) & & & n/a \\
\hline Suture of collecting system & & & 0.07 \\
\hline Hospital stay & $3.42 \pm 0.6(3-4)$ & $4.6 \pm 1.3(3-7)$ & \\
\hline
\end{tabular}

Table 1

CORRELATION BETWEEN TYPE OF SUTURE UTILIZED FOR

RENORRHAPHY, TOTAL OPERATIVE TIME, ESTIMATED BLOOD LOSS AND WARM TIME ISCHEMIA

\begin{tabular}{|l|c|c|c|}
\hline & \multicolumn{2}{|c|}{ Medium risk Zonal NePhRO score } & P value \\
& \multicolumn{2}{|c|}{ Bicri1 $^{\text {TMI Group }}$} & \\
\hline & V-loc ${ }^{\text {TM }}$ Group & 7 & n/a \\
\hline Patients & 4 & $140.7 \pm 23.7(105-170)$ & $<0.001$ \\
\hline Operative time (min) \pm SD (range) & $115.5 \pm 21.8(90-165)$ & & 0.1 \\
\hline Blood loss (ml) \pm SD (range) & $165.0 \pm 38.4(140-210)$ & $188.5 \pm 84.1(150-250)$ & 0.001 \\
\hline Warm ischemia time(min) \pm SD (range) & $17.7 \pm 2.94(16-22)$ & $20.8 \pm 3.1(14-24)$ & $n$ \\
\hline Suture of collecting system & $1(25 \%)$ & $4(57.1 \%)$ & 0.04 \\
\hline Hospital stay & $3.2 \pm 0.4(3-4)$ & $4.0 \pm 0.8(3-5)$ & \\
\hline
\end{tabular}

Table 2

MEDIUM RISK ZONAL NePhRO SCORE (7-9)

\begin{tabular}{|l|c|c|c|}
\hline & \multicolumn{2}{|c|}{ High risk Zonal NePhRO score } & P \\
& \multicolumn{2}{|c|}{ value } \\
\hline & V-loc ${ }^{\text {TMI Group }}$ & Bicril ${ }^{\text {TMI Group }}$ & \\
\hline Patients & 5 & 5 & n/a \\
\hline Operative time (min) \pm SD (range) & $158.0 \pm 21.1(140-170)$ & $184.0 \pm 29.9(160-230)$ & $<0.001$ \\
\hline Blood loss (ml) \pm SD (range) & $242.0 \pm 125.7(170-400)$ & $344.0 \pm 232.3(190-750)$ & 0.01 \\
\hline Warm ischemia time(min) \pm SD (range) & $22.2 \pm 3.1(20-26)$ & $30.8 \pm 5.4(25-39)$ & $<0.001$ \\
\hline Suture of collecting system & $5(100 \%)$ & $5(100 \%)$ & $n$ \\
\hline Hospital stay & $4.0 \pm 0.7(3-5)$ & $5.4 \pm 1.0(4-7)$ & 0.009 \\
\hline
\end{tabular}

Table 3

HIGH RISK ZONAL NePhRO SCORE (10-12) 

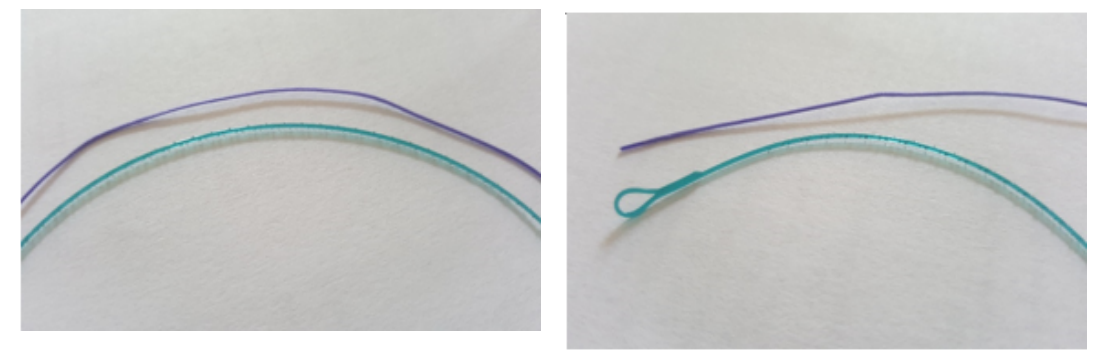

Fig. 1 Standard suture material - Bicril ${ }^{T M}$ (violet) and unidirectional barbed suture-V-loc ${ }^{\mathrm{TM}}$ (green)

Both suture materials used for renorrhaphy present good outcomes in terms of biodegradability [7, 10], the suture requiring a good tensile strength for over a month in order to maintain good hemostasis and facilitate renal healing. Another important issue is bacterial adhesion witch seems to favor polydioxanone use over polyglicolic acid [11].

The design of $\mathrm{V}-\mathrm{Ioc}^{\mathrm{TM}}$ with an end-tail loop gives the surgeon to perform a knotless renorrhaphy, with only one Hem-o-lock ${ }^{\mathrm{TM}}$ placed at the end of the suture, reducing the cost of the surgery when comparing to multiple Hem-olock ${ }^{T M}$ placing technique throughout the suture, Hem-olock ${ }^{\top \mathrm{M}}$ clips representing an effective fixation system according to Grigore et al [12].

\section{Conclusions}

$\mathrm{V}-\mathrm{IOC}^{\mathrm{TM}}$ suture is a safe and effective unidirectional barbed suture, reducing the warm time ischemia and obtaining a good hemostasis in laparoscopic nephron sparing surgery when compared with standard absorbable suture.

Further large scale prospective studies with long-term follow-up and direct comparison with novel developed sutures are needed in order to confirm the place of unidirectional barbed suture in the urologist armamentarium.

Acknowledgements: This study, being a retrospective one, did not require a written consent from the patients involved. The authors declare no conflict of interests and no sponsorship was provided by the manufacturer of the suture materials involved in this study. All authors have read and approved this publication and had equal scientific contribution in publishing this material.

\section{References}

1.BLADOU F. Indications and the Role of Laparoscopic Partial Nephrectomy, European Urology Supplements, 2010, 9:454-458 2.KIM HS, LEE YJ, KU JH, KWAK C, KIM HH, JEONG CW. The clinical application of the sliding loop technique for renorrhaphy during robot- assited laparoscopic partial nephrectomy: Surgical technique and outcomes. Korean J Urol., 2015, 56:762-768

3.SAMMON J., PETROS F., SUKUMAR S. ET AL., Barbed suture for renorrhaphy during robot-assisted partial nephrectomy, J. Endourol. 2011, 25:529-533

4.XU W, LI H, ZHANG Y, ZHANG X, JI Z, Comparison of Standard Absorbable Sutures with Self-Retaining Sutures in Retroperitoneoscopic Partial Nephrectomy: A retrospective Study of 68 Patients, Laparoscopic Urology, 2014, 11 (5): 1878-1883

5.ERDEM S., TEFIK T., MAMMADOV A. ET AL., The use of Self-retaining Barbed Suture for Inner Layer Renorrhaphy Significantly Reduces Warm Ischemia Time in Laparoscopic Partial Nephrectomy: Outcomes of a Matched Pair Analysis, J. Endourol. 2013, 27:452-458 6.KAYGISIZO., CELEN S., VURUSKAN B.A., VURUSKAN H., Comparison of two different suture techniques in laparoscopic partial nephrectomy, 2017,43

7. AMES A GREENBERG, RACHEL M. CLARK. Advances in Suture Material for Obstetric and Gynecologic Surgery, Rev Obstet Gynecol. 2009, 2 (3):146-158

8.KADIRKAMANATHAN S.S., SHELTON J.C., HEPWORTH C.C. ET AL., A comparison of the strength of knots tied by hand and at laparoscopy, J Am Coll Surg. , 1996, 182:46-54

9.LOPEZ P.J., VENESS J., WOJCIK A., CURRY J., How reliable is intracorporeal laparoscopic knot tying?, J Laparoendosc. Adv. Surg. Tech. A., 2006, 16:428-432

10.NICULESCU M, ANTONIAC A, VASILE E, SEMENESCU A, TRANTE O, SOHACIU M, MUSETESCU A, Evaluation of Biodegradability of Surgical Synthetic Absorbable Suture Materials: An In Vitro Study, Mat. Plast., 53, no. 4, 2016, p. 642

11.GRIGORAS RI, COPOTOIU C, COSARCA AS, FULOP E, MARE A, BARBU HM, HANCU V, COMANEANU RM, SUCIU VI, ORMENISAN A, In vitro Study About Bacterial Adhesion to the Surface of Suture Materials Used in Oro-maxilo-facial Surgery, Mat. Plast., 53, no. 3, 2016, p. 501 12.GRIGORE N, PIRVUT V, MIHAI I, CERNUSCA MITARIU SI, SAVA M, HASEGAN A. Mat. Plast., 54, no. 2, 2017, p. 29

$\overline{\text { Manuscript received: } 26.10 .2017}$ 